\title{
Fetal \& Neonatal Outcomes of the Magnesium Sulfate and Nefidipine in Suppression of Preterm Labor
}

\author{
Fahimeh Sehhati Shafaie 1*, Fereshteh Fartash ${ }^{1}$, Zahra Fardiazar ${ }^{2}$, \\ Morteza Gojazadeh ${ }^{3}$
}

\section{Article History:}

Received 1 December 2013

Accepted 3 February 2014

Revised 17 January 2014

Available online 4 February 2014

\section{Keywords:}

Fetal-Neonatal Outcomes

Nefidipin

Preterm Labor

Sulphate Mg

\section{Corresponding Author:}

Fahimeh Sehhati Shafaie, MSc Academic Member of Nursing and

Midwifery Faculty, Tabriz University of Medical Sciences Tabriz, Iran.

Tel: +989143014293

Email: sehhatief@tbzmed.ac.ir

\begin{abstract}
Objectives: Preterm Labor occurs in $11.8 \%$ of all pregnancies and is the most etiology of Neonatal morbidity without Anomalies and after intra partum congenital Anomalies is the second etiology of Neonatal mortality that has high economic \& psychiatric cost. Premature infants have Neurotic complications and they are week about physical growth, practical cognitive and lesson tasks. One of usage drugs in prevention of preterm labor is Nefidipin.

Materials and Methods: This research is a Double blind RCT. All of pregnant mothers with 26-34 weeks with signs of preterm labor have come to Alzahra \& Talegani hospitals were research population. Research samples were 80 pregnant women that have eligibility criteria and treated with Sulphate mg \& Nefidipin. Samples allocated randomly in 2 groups by use of rand list soft ware and block of 3 and 6.In group A were used Sulphate mg $4 \mathrm{~g}$ first and then $2 \mathrm{~g} / \mathrm{h}$ for $48 \mathrm{~h}$ and group B were used Nefidipin $20 \mathrm{mg}$ first and $20 \mathrm{mg} / \mathrm{half} \mathrm{h}$ after. Success of treatment was measured by Partograph \& checklist .Data was analyzed by statistic tests and spss ver. 13 .

Results: Neonatal complications such as 1 min Apgar and 5 min Apgar score, Sao2 and ABG in 2 groups, that treatment could not prevent contractions, have not significantly different. But there were significant different about Fetal complications such as bit to bit variation, decrease of fetal movement and dropt of base line of FHR ( $\mathrm{p} \leq 0.05)$.

Conclusion: Data showed that Nefidipine was more effective in comparison of Sulphate $\mathrm{mg}$ in suppress of uterus contractions and improve of feto-Neonatal outcomes that these will prevent further Growth \& Development complications in Neonatal and this drug can be best supplement for Sulphate mg in suppress of preterm contractions of uterus.
\end{abstract}

1 - MSc ,Academic Member of Nursing and Midwifery Faculty, Tabriz University of Medical Sciences , Tabriz, Iran.

2- MD, Academic member of Medicine Faculty, Tabriz University of Medical Sciences, Tabriz, Iran.

3- PhD, Academic member of Medicine Faculty, Tabriz University of Medical Sciences, Tabriz, Iran. 


\section{Introduction:}

Nowadays the rate of premature birth called "preterm labor" is high causing many problems for both the mother and the baby (1). Preterm labor is the leading cause of death in a newborn without anomalies. After birth defects, premature labor is the second main cause of neonates' mortality. This imposes a high economic and psychological cost to the society (2). Preterm labor occurs in $11.8 \%$ of various races (3). Babies born before 24 weeks gestation do not survive and the ones who survive are less likely to be healthy and are at increased risk of health problems (4). It also increases the risk of respiratory distress syndrome (RDS) among these group caused by lack of surfactants secretion. However fetus at 26-34 weeks that complete dosage of betamethasone $48 \mathrm{~h}$ before delivery, the mortality and RDS morbidity rates are significantly decreased. Antenatal glucocorticoid administration can significantly reduce RDS and other problems including intra ventricular hemorrhage (IVH), patent ductus arteriosus (PDA), pneumothorax, necrotizing enter colitis (5). Infants born preterm are at risk of various neurological complications. Neurodevelopment squeal in preterm infants include cerebral palsy, seizures, hydrocephalus, blindness, deafness and cognitive impairment. The risk of an adverse outcome increases with decreasing gestational age at birth (2). Early morbidity and prognostic variables that contribute to adverse neurodevelopment outcomes are include: grades 3-4 intraventricular hemorrhage, necrotizing entro colitis, periventricular leukomalacia, neonatal infections and Broncopulmonary dysplasia (6). At school age VLBW newborns have poorer physical growth and cognitive function as well as school performance (3). The final goal of treating preterm labor is to prolong of pregnancy in the patients and delay delivery for at least 48 hours so it allows corticosteroid treatment to improve fetal lung maturity (1). Much research has been conducted regarding the prevention of or minimizing the complication of premature labor. Various treatments have also been proposed among this group of patients. Although pharmacological suppression of contractions is the most common treatment (7), there is still disagreement on the best method of treatment. Some pharmacological compounds are used to suppress uterine contractions in women with preterm labor (8).

The medicines used to suppress preterm labor are including Ritodrine, Magnesium sulfate and Calcium channel blockers (1). The effects of relaxant agents in suppression of preterm labor has not been proven, yet (9). Preterm labor is the main reason for early death among $85 \%$ of premature infants (10). previous studies about this subject and necessity of this study is to compare the effects of magnesium sulfate and nefidipine to suppress preterm labor. We also evaluate fetal and neonatal complications due to magnesium sulfate and nefidipine administration.

\section{Material \& Methods:}

This was a double-blind, randomized clinical trial conducted in Alzahra and Taleghani Medical Educational Centers in Tabriz. Research samples were 80 pregnant women that allocated randomly in 2 groups by use of rand list soft ware and block of 3 and 6.Inclusion criteria's included women with gestational age of 26-34 weeks having regular uterine contractions lasted about 2030 seconds, at least one contraction every 10 minutes, with cervical dilation of (maximum) 2-3 cm, cervical effacement of $50 \%$ or less, feeling of pressure in the pelvis, low back pain and vaginal discharge. Entering the labor room written informed consent was taken by the all participants. For the women in magnesium sulfate group an initial loading dose of $4 \mathrm{~g}$ was given intravenously and then $2 \mathrm{~g}$ every one hour provided that a patellar reflex was present, urine output during the proceeding half an hour exceeds $30 \mathrm{ml}$, and respiration exceeds 12 per minute. For the patients in the nefidipine group initially received $20 \mathrm{mg}$ of oral nefidipine, $20 \mathrm{mg}$ nefidipine was given again if the contractions continued after half an hour. If not, subsiding $20 \mathrm{mg}$ was continually administered every 3-8 hours up to 48 hours. Treatments were discontinued 
if contractions progressed. The contraindications of administration of nefidipine included: maternal hypotension (systolic BP less than $9 \mathrm{mmHg}$ ), Liver dysfunction, recent intake of magnesium sulfate. The data from the study were analyzed using statistical descriptive method (frequency, percentage and mean \pm standard deviation), statistical tests (independent sample t-test), and Chisquare test. In this study $\mathrm{P}<0.05$ was considered statistically significant.

\section{Results:}

In the magnesium sulfate group, decreasing the frequency of fetal movement was $27.5 \%$. While heart rate reduction from baseline was $57.5 \%$ and fetal heart rate exchanges was decreased in $37.5 \%$. None of these changes were seen in the nefidipine group. Comparison showed significant difference in fetal heart rate and reduction of fetal movement, changes in baseline state and heart rate changes. (Table - 1)

No significant difference in neonatal outcomes was showen between the two groups (the first and fifth minute Apgar score, admission to NICU, Sao2, PH, PCO2, P02, HCO2, BE). (Table - 2)

\section{Discussion:}

Results of the study showed that the significant differences in the drug effects on fetal movement as well as baseline fetal heart rate. In the magnesium sulfate group the baseline fetal heart rate (signed in monitoring device) dropped by $10-20$ beats. In addition, the heart rate changes were less than the fetal heart rate, appears similar to sinusoidal pattern. Hallak et al (1999) conducted a study titled: "The effects of magnesium sulfate on fetal heart rate parameters". Findings showed that magnesium sulfate administration resulted in decreased fetal heart rate baseline values and variability which was consistent with the present study (11). According to the results of a study by Fujimori et al (2004), "The effects of magnesium sulfate on behavioral activities of fetal goats", incidence of fetal heart rate accelerations during magnesium sulfate infusion was significantly decreased, that these are also consistent with the current study (12).
Regarding arterial blood gas (ABG) measurement, there was no significant statistical difference between two groups in the first and fifth minute Apgar score, admission to NICU, Oxygen saturation, $\mathrm{PH}$, CO2, PO, HCO3, BE. Edwin \& Sabaratnam (2005) reviewed 12 researches and then published an article titled: "Recent advances in management of preterm labor". They concluded that calcium channel blockers can reduce the incidence of respiratory distress syndrome, necrotizing enter colitis, intraventricular hemorrhage and neonatal jaundice. In this study magnesium sulfate infusion resulted in high fetal complications (6). These results are consistent with our findings. This difference is from the fact that, in our study ABG was only measured in those neonates who had failed treatment and delivery was unavoidable. Before completion of Betamethason intake, all of the 21 preterm neonates were born. Therefore, all of them were admitted to NICU with respiratory distress syndrome. But in the study by Edwin et al, all of the newborns were assessed after birth regardless whether born before or after completion of Betamethasone intakes.

\section{Conclusion :}

In this study we compared effects of magnesium sulfate and nefidipine for suppress of preterm labor. Findings showed that nefidipine was more efficient than magnesium sulfate in suppress of uterine contractions. Yet, nefidipine is associated with improved fetal and neonatal outcomes such as fetal heart rate and fetal movement, changes in baseline state and heart rate changes compared to the magnesium sulfate agent; thus the difference is significant. We suggest that nefidipine use for suppression of preterm labors in Hospitals.

\section{Conflicts of interest:}

Authors declare that there is no any conflict of interest.

\section{Acknowledgments:}

The author would like to thank all the staff of NICU, labor and delivery wards of Tabriz Alzahra and Taleghani Medical Education Centers who shared their time and experience with us. If this study is part of 
student's thesis, please add this sentence" The results described in this paper were part of student thesis.IRCT201201308878N1

Table 1: Comparison of fetal outcomes of the study groups separately.

\begin{tabular}{|c|c|c|c|c|c|}
\hline \multirow{3}{*}{ Variables } & \multicolumn{4}{|c|}{ Groups } & \multirow{3}{*}{$\mathbf{P}$} \\
\hline & \multicolumn{2}{|c|}{ Magnesium sulfate } & \multicolumn{2}{|c|}{ Nefidipine } & \\
\hline & Reduction & No change & Reduction & No change & \\
\hline $\begin{array}{c}\text { Fetal } \\
\text { movement }\end{array}$ & $11(27.5)$ & $29(72.5)$ & $0(0)$ & $40(100)$ & $<0.001$ \\
\hline $\begin{array}{l}\text { Fetal baseline } \\
\text { heart rate }\end{array}$ & $23(57.5)$ & $17(42.5)$ & $0(0)$ & $40(100)$ & $<0.001$ \\
\hline $\begin{array}{c}\text { Fetal heart } \\
\text { rate changes }\end{array}$ & $15(37.5)$ & $25(62.5)$ & $0(0)$ & $40(100)$ & $<0.001$ \\
\hline
\end{tabular}

Table 2 : Neonatal characteristics.

\begin{tabular}{|c|c|c|c|c|}
\hline \multirow{2}{*}{\multicolumn{2}{|c|}{ Variables }} & \multicolumn{2}{|c|}{ Groups } & \multirow{2}{*}{$\mathbf{P}$} \\
\hline & & Magnesium sulfate & Nefidipine & \\
\hline \multicolumn{2}{|c|}{ First minute Apgar score } & $7.38 \pm 1.07$ & $5.6 \pm 1.51$ & 0.7 \\
\hline \multicolumn{2}{|c|}{$\begin{array}{l}\text { Fifth minute Apgar } \\
\text { score }\end{array}$} & $8.47 \pm 1.12$ & $8.8 \pm 1.3$ & 0.57 \\
\hline \multicolumn{2}{|c|}{ Admission to NICU } & $1 \pm 0.001$ & $0.8 \pm 0.44$ & 0.37 \\
\hline \multirow{6}{*}{$\begin{array}{l}\text { Neonatal } \\
\text { ABG }\end{array}$} & $\mathrm{SaO} 2(\%)$ & $80.04 \pm 17.65$ & $85 \pm 13.5$ & 0.56 \\
\hline & $\mathrm{PH}$ & $6.35 \pm 2.35$ & $6.16 \pm 2.56$ & 0.87 \\
\hline & PCO2(\%) & $31.95 \pm 1.8$ & $30.3 \pm 2$ & 0.86 \\
\hline & PO2(\%) & $28.69 \pm 2.32$ & $30.54 \pm 2.77$ & 0.87 \\
\hline & $\mathrm{HCO} 3$ & $17.77 \pm 7.2$ & $14.9 \pm 7.67$ & 0.43 \\
\hline & $\mathrm{BE}$ & $-2.9 \pm 5.7$ & $-4 \pm 1.73$ & 0.69 \\
\hline
\end{tabular}




\section{References:}

1. Gary Cunningham F, Kenneth J, Steven L, John C, Dwight J, Catherine Y.Williams Obstetrics. 23ed.Tehran: Golban Publishers; Chapter 36, 2010; 804-805.

2. Kliegman R, Behrman R, Jenson H, Stanton B. Nelson Textbook Of Pediatrics. 1 18e. Tehran: Golban Publishers; 2007; 64-66.

3. Han S, Crowther CA, Moore V. Magnesium maintenance therapy for preventing preterm birth after threatened preterm labour.(Review).The cochrane library . 2010; 7:1-2-4-5

4. Haas DM, Imperiale TF, Kirkpatrick PR. Tocolytic therapy: a meta-analysis and decision analysis. Obstet Gynecol.2009; 113:585-594

5. Michal J, Mordechai D, Shlomo M, Steven A, Friedman J, Eyal S. Adjustment of magnesium sulfate infusion rate in patients with preterm labor. Am J Obstet Gynecol. 1998 ; 179(4): 994-8.

6. Edwin C, Sabaratnam A. Recent advances in management of preterm labor. J Obstet Gynecol India. 2005; 55(2):121-2.

7. Caughey M, Ahsan A, Hopkins M. Blueprints Clinical Cases in Obstetrics and Gynecology. 2nd ed. Lippincott Williams \& Wilkins Publisher; 2012; 502-504.

8. Susan S, Terri K. Maternity and Pediatric Nursing. Har/Cdr ed. Lippincott Williams \& Wilkins Publisher; 2008;646-647.

9. Haghighi L. Prevention of preterm delivery: nifedipine or magnesium sulfate. International Journal of Gynecology \& Obstetrics. 1999; 66:297-298.

10. Nandita M, Vincent CH, Verma R, Desai V. Maternal and fetal cardiovascular side effects of nifedipine and ritodrine used as tocolytics. J Obstet Gynecol India. 2007; 57(2):131-4.

11. Hallak M, Martinez-Poyer J, Kruger ML, Hassan S, Blackwell SC, Sorokin Y. The effect of magnesium sulfate on fetal heart rate parameters: A randomized, placebo-controlled trial. Am J Obstet Gynecol. 1999; 181(5 Pt 1):1122-7

12. Fujimori K, Ishida T, Yamada J, Sato A. The effect of magnesium sulfate on the behavioral activities of fetal goats.Pubmed. 2004; 103(1):137-42. 